\title{
Situational Problems as a Means for Forming the Professional Competencies of University Students
}

\author{
Yuliya L. Kamasheva ${ }^{1}$, Zulfina S. Aglyamova ${ }^{1}$, Sergey P. Yakovlev ${ }^{2}$, Elena V. Konovalova ${ }^{3}$, Anna S. Zhuravleva ${ }^{3}$, \\ Ramil H. Mingazov ${ }^{4} \&$ Maja V. Polyakova ${ }^{3}$ \\ ${ }^{1}$ Institute of Economics, Management and Law, Kazan, Russia \\ ${ }^{2}$ Saint Petersburg State University of Engineering and Economics in Cheboksary, Cheboksary, Russia \\ ${ }^{3}$ Chuvash State Pedagogical University named after I. Y. Yakovlev, Cheboksary, Russia \\ ${ }^{4}$ Kazan (Volga region) Federal University, Kazan, Russia \\ Correspondence: Yuliya L. Kamasheva, Institute of Economics, Management and Law, Moskovskaya Street, 42, \\ Kazan, 420111, Russia. E-mail: kamasheva@ieml.ru
}

Received: April 16, 2015 Accepted: April 26, 2015 Online Published: May 28, 2015

doi:10.5539/jsd.v8n3p162 URL: http://dx.doi.org/10.5539/jsd.v8n3p162

\begin{abstract}
The purpose of this article aims to study the problem of forming students' competencies during the professional training in the university. The paper demonstrates a methodology for the development and application of situational problems as an effective means of forming the professional competencies of university students. The basis of the presented work is the ideas of the competence-based and the activity-based approaches, expert evaluation of the university students' educational activity. The article describes the technology for developing the situational problems, based on the analysis of the professional roles. This article is intended for educators, researchers, and heads of educational institutions that are into the formation and diagnostics of university students' professional competencies.
\end{abstract}

Keywords: higher education, activity-based approach, competence-based approach, professional competencies, situational problems

\section{Introduction}

\subsection{Background}

In terms of the economic reforms taking place in Russia and the development of the industry on a new technological level, the issue of training the specialists able to solve increasingly complex technical and technological problems, to develop their professional competence in accordance with the dynamically changing requirements, is becoming extremely important. Almost all modern technical, technological and natural science professions differ in the use of the latest tools and technologies.

A modern graduate must meet the following general eligibility requirements: to work effectively in his/her chosen profession; to be able to quickly absorb new information in large volumes; to show the necessary mobility in the review of beliefs in the field of the specialty; to have the possibility of transferring to another area when it is necessary and to adequately quickly, effectively master it.

To achieve these goals flexible curricula are being created, allowing for changes in the content, the volume and the speed of learning. Firstly, the ability to analyze and synthesize comes, as well as the ability to quickly grasp the essence of the basic principles, regulations and processes. In modern pedagogical practices there has been developed and applied quite a large number of new and innovative educational models based on active, creative activity of students in the learning process and designed to enrich the activities of higher education institutions, improving the quality of education and expanding its availability.

These models can also include a theory of task-based technology for training students, which reveals the essence of the students' cognitive activity, describes the levels of their cognitive independence, determining the compliance with the requirements of the modern society. 


\subsection{The Status of the Problem}

Modern educational standards, involving a highly skilled worker, who is competitive in the labor market, competent, responsible, fluent in his/her profession and feeling confident in related fields of activity, as well as capable of effective creative jobs, require the inclusion of active and interactive methods of teaching in the educational process.

In the process of technical, technological and scientific training, the solution of problems is crucial, and represents a significant portion of disciplines, such as physics, mathematics, chemistry and their derivatives.

The solution and the problem analysis allow us not only to understand and remember, but also to make sense from a practical point of view of the basic laws and formulas of the object, create an idea about their features and the boundaries of application. The problems develop skills in the use of general laws of the material world to address specific issues with practical and informative value. The educational problem is not only seen as a means to consolidate knowledge and skills, but also as the main means to form the basic concepts of mathematics and science disciplines and to develop creative thinking of students. The ability to solve problems is the best criterion for assessing the depth of studying the material and its acquisition.

The application of training tasks in the learning process, their classification, problem functions were considered in the works of psychologists and didacts G. A. Balla, G. D. Bucharova, I. K. Zhuravleva, Z. I. Kalmykova, V. V. Larionov, A. N. Leontyev, I. Ya. Lerner, M. I. Makhmutova, N. A. Menchinskaya, A. A. Tolstenova, L. M. Friedman, and others (Ball, 1990; Buharova, 1996; Kalmikova, 1981; Larionov, 1998; Leontiev,1983; Lerner, 1969; Makhmutov, 1975; Tolsteneva, 2008; Friedman, 1977).

The results of final examinations in high comprehensive schools, of entrance and current exams in universities, the overall results of national testing and the unified state exam (USE) show that the process of solving problems is a weak link in the study of natural science and mathematical subjects.

Thus, there is a contradiction between the high level requirements of modern society to the quality of training competent professionals and the low level of practice-oriented activities of students in the subject area of natural sciences and mathematical disciplines at a high potential task-based method using situational problems as a means of forming the professional competencies.

\subsection{The Research Hypothesis}

A distinctive feature of the competence-based approach is the formation of abilities to use knowledge in practice, the lack of tight binding to the specific object and the subject of labor that ensures the mobility of the future specialists in the changing conditions of the modern labor market. The manifestation of professional competencies involves continuous renewal and growth of professional knowledge, acquirement of new information for the successful solution of professional tasks under the specified conditions.

The efficiency of the process of forming professional competencies will be significantly improved, if in the process of professional training of a student to include a set of situational problems, created on the training content, the real issues and emerging professional situations.

Situational problems allow integrating the totality of a student's knowledge, expanding his/her educational space and awareness, contributing to the definition and understanding of interdisciplinary connections, the system of interaction between science, practice and professional activities.

The solution of situational problems, based on the involvement of a student in active learning, allows learning to use knowledge creatively and actively.

\section{Materials and Methods}

\subsection{The Theoretical and Methodological Framework of the Research}

The theoretical framework of the formation of professional and general cultural competencies of future specialists in the science and mathematics training on the basis of situational problems is the competence-based and the activity-based approaches ensuring the integrity of the science and practice, defining the procedures for the educational activities of a teacher and a student.

The competence-based approach identifies the modern professional education framework, determining the effectiveness of the activities, and, consequently, its content (Zeer, 2005; Zimnya, 2006, etc.). This approach is objectively interconnected with other approaches, integrating their essence to achieve the necessary competencies of students and to develop personality in the professional training. The competence-based approach in a greater degree meets economic and social needs, creating a balance between the demand on the 
labor market and the interests and professional realization of an individual.

The formation of professional and general cultural competencies should occur in the process of an activity based on the formation and development of personal qualities of the future university graduates. The technological level of this aspect provides the activity-based approach to the pedagogical process.

The activity-based approach theory emerged in the national psychology quite long ago (Vygotsky,1996; Rubinstein, 1958; Leontiev,1983; Davydov, 2006; Galperin, 1978), its basis is the statement about the formation of the personality traits of a person (a subject) in activities, that is, the unity of activity and consciousness. The activities (transformative, informative, value-motivational, and communicative) form a closed, self-developing system. Each person is simultaneously involved in the conservation and development of human experience in any field, changing it over time on the basis of the contradictory tendencies of adaptation, as an activity in the pre-defined framework and innovation, as active actions that change the system.

\subsection{The Task-Based Learning Methods as a Way to Build up Competencies}

Learning through activities (J. Dewey's idea) (Dewey, 1999) and independent search for the solution of the set problems through knowledge has formed the basis of the modern methods of active learning, contributing to the acquisition of the necessary professional behavior by the individual. Effective organization of the educational activity is not built on the translation of a teacher's knowledge, but on the joint activities of the teacher and the student, aiming to achieve the operative, tactical and strategic goals.

According to Dewey, a teacher needs to monitor closely the development of the interests of students and "toss them the problems feasible for understanding and solving". Students should be assured that, by solving these problems, they discover new knowledge.

These provisions correlate with the theory of problem-based learning обучения (Makhmutov, 1985; Okon, 1968) and are based on the provisions of the problematic nature of thought, the origin of mental activity in a problem situation (Rubinstein, 1958).

Problem-based learning is based on the acquisition of new knowledge by solving theoretical and practical problems, problem tasks and on the created, therefore, problematic situations (Makhmutov, 1975). A problematic situation arises in the learning process when a student has a cognitive need, intellectual abilities to solve a problem and when there are difficulties, contradictions between old and new, known and unknown, the data and the desired, conditions and requirements (Mukhametzyanova, 2005).

The main difficulty in the problem-based learning - is the selection of problem situational tasks, which must satisfy the following conditions: must arouse a learner's interest; be available to his/her understanding; lie in the "zone of proximal development"; give subject knowledge in accordance with the curricula and programs; develop professional thinking.

\subsection{The Main Provisions of the Task-Based Method}

Relying on the definition of the task-modular technology (Kabirov, 2005), we will demonstrate its basic concepts:

- organization of students' own cognitive activity;

- focuses on the development of students' own activity;

- a teacher acts as a facilitator instead of like a basic element of the educational activities;

- implementation of the "complete act of thought": a person starts to think when faced with difficulties (problem);

- training programs are developed on a case-by-case basis;

- the main forms of training - are theoretical and practical classes, in which students' independent research work is carried out on the solution of situational problems.

\section{Results}

\subsection{The Model of a Situational Problem}

The necessity of introducing a task-based method, developing the situational problems, as one of the types of active and interactive learning, contributing to the formation of professional and general cultural competencies of university students, was motivated by the desire to achieve a new quality of geographical education which meets modern requirements of social development. 
This training is based on a direct, productive interaction of all participants of the educational process and uses a situational problem, as a technique providing a solution for a practically relevant situation for the purpose of forming the constituents of professional education.

Situational problems are focused on the formation of the most versatile ways of working with information, which are based on the taxonomy developed by B. Bloom (Bloom, 1956). The solution of situational problems involves several sequential steps: target, updating, problem, tools selection, theoretical, productive, generalization.

A typical situational problem includes:

- description of the conditions (subject environment);

- the problem statement (the occurrence of an unanticipated situation requiring solution);

- a student-significant cognitive question;

- additional information (reminder or learning);

- tasks (questions) for solution.

The type of a problem depends on the level of the student, his educational path, the evaluative differentiation. The solution to many situational problems is associated with the analysis of specific situations that reflect what is happening in professional fields.

The situational problems are aimed at implementing the following functions: organization of informative and independent activity, resulting and corrective functions.

The procedure of the situational problems composition directly depends on the level of professional training of students, so in the junior years of a university, the tasks on the basis of the theoretical framework of the discipline can be used, then, when mastering some professionally-oriented disciplines - on the selected types of practice-oriented tasks that need to be learned how they should be solved by each student (minimal competencies), at the undergraduate level, in the implementation of research activities of students, real professional problems may be used on the material relevant to the student.

Designing of such situational problems - is a creative pedagogical process representing the result of reflection on professional experience in the study of the subject area.

The source of the content of the practical training is the professional activity of a specialist, or rather, the professional tasks that make up the content of the professional activity. The ratio of the major sources of a situational problem (Matkarimova, 2012) may be different: practical situations that reflect real life situations; learning situations, the primary objective of which is the training; scientific-research situations, focused on the implementation of research activities. The requirements for a situational problem, in our view, include: a real professional situation; an emerging professional conflict (a controversial issue), the tension of the situation (possibly the urgency of the solution), the complexity and polysemy of the problem, the clarity of the description of actors of a problem or situation, multivariate solutions, conditions-restrictions, excessive descriptiveness.

\subsection{Examples of the Situational Problems}

The generalized experience of studying the situational problems allows giving the following examples:

1) A situational problem for a future doctor ("Physics and mathematics" discipline). Situation: a patient comes complaining of pain in his heart (the role of the patient is performed by another student), it is necessary to make a diagnosis and suggest treatment methods (the task includes: analysis and enumeration of physical methods used for diagnosis in this situation, possible in this situation physical therapy and surgical intervention; knowledge and explanation of the assignment and configuration of the device to the students; the ability to do the electrocardiogram; the analysis of the performance of the device, the answers to the raised theoretical questions);

2) A situational problem for a future manager ("Mathematics" discipline). The situation: managerial decision making by a future production manager when determining the factors of his productivity.

The store buys one type of products from two vendors. You need to evaluate the supply strategy, despite the fact that the existing volume cannot be reduced. It is necessary to develop a mathematical programming model that takes into account all the factors affecting the decision, taking into account transport costs. The task includes knowledge of the methods of linear programming, mathematical models of linear programming problems; definition of the problem constraints and the objective function, the formalization of the set problem, finding the optimal solution using a mathematical method, building up the draft decision with satisfactory prediction of the results. 
3) A situational problem for a future engineer-ecologist ("Chemistry" discipline). The situation: there is the result of the analysis of drinking water (the data is shown). Give hygienic conclusion on the problem and describe the possibilities of disinfecting it using chloride lime. The task includes knowledge of the water system, its types; methods of water disinfection, the calculation of the chlorine dose, the dechlorination methods, knowledge of diseases from contaminated water.

\subsection{An Experiment on the Formation of Professional Competencies through the System of Situational Problems}

We consider the professional training of a production manager at a university, and its component - mathematical training.

One of the key components of this success of managers a high level of mathematical training can be considered, which enables, through the use of mathematical methods (for example, by methods of mathematical statistics, optimization, simulation, etc.) to explore a wide range of issues and to apply modern software tools to automate the process and increase the objectivity of the results. The need to enhance the process of mathematical training of students - the prospective production managers - is due to not only the importance of the discipline and its substantive content, but also the connection of this discipline with the profile of their future profession. It is important that the mathematical content of training a production manager should reflect the scientifically-based composition of professionally-requisite knowledge, skills, abilities and competencies.

As a result of studying the basic and optional parts of mathematical subjects (mathematics, theory of statistics, socio-economic statistics) the graduates of the bachelor degree in "Management" must: a) know the basic concepts and tools of algebra and geometry, mathematical analysis, probability theory, mathematical and socio-economic statistics; basic mathematical models of decision making; b) be able to solve common mathematical problems used in making managerial decisions; use mathematical language and mathematical symbols when building organizational and management models; c) possess mathematical, statistical and quantitative techniques for solving typical organizational and managerial tasks. The importance of mathematical training for the professional training of the manager is obvious: the mathematical sciences design methods, which, being based on their diversity and universalism, can be used to analyze and solve a variety of economic, financial or business problems. The fundamental mathematical knowledge is the basis for forming the knowledge in management, marketing and economics in the industrial sector.

Obviously, for the development of abilities of a prospective manager, the formation of the required professional competencies, gaining experience, it is necessary to carry out the simulation of the professional activity in the professional training, to solve the training professionally-oriented situational problems, implement the actions inherent to their future profession. In this aspect, the subjects of the mathematical cycle, along with special economic disciplines, constitute the basis of forming the necessary qualities of a future manager.

Based on the research and analysis of the future professional activity of a manager we have made and systematized situational problems. A database of educational tasks has been compiled, focused on the development of the necessary professional and personal qualities of a future production manager (the skills and knowledge of various levels). In the course of the mathematical training of a future manager (covering 1-3 courses), focusing on the development level, the students are expected to solve these case studies, the evaluation of which is included in the final grade for the completed course.

In the experiment, the professional competencies were assessed as: the ability to formalize the set problem (A-abilities); the abilities of a manager to build up a project for solution with satisfactory prediction of the results (B-abilities); the ability to implement and carry out the solution control (C-abilities), being shown on low, medium and high levels (Adigamova, 2014).

The conducted pedagogical experiment (covers 193 students of Kazan National Research Technical University), built on the comparison of the control groups (mathematical training according to the traditional procedure) and the experimental groups (mathematical training on the basis of situational professionally-oriented tasks during the entire period of study (4 years)) showed significant changes in the formation of the professional qualities of a prospective manager (Fig.1). 


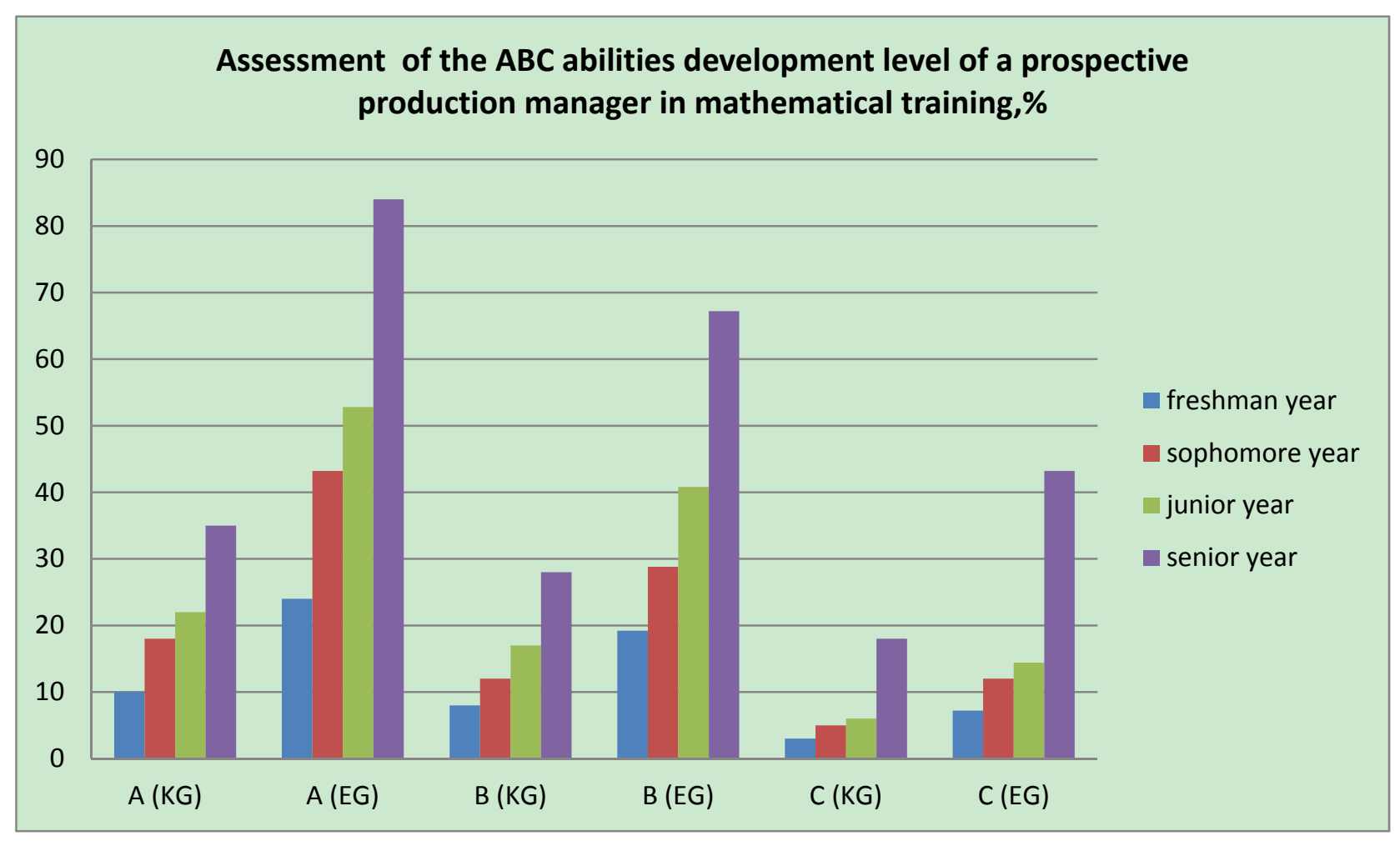

Figure 1. Dynamics of the ABC abilities development of a prospective manager in the experimental and control groups

The level of knowledge, skills, ability to make and monitor decisions are significantly higher in the experimental group (36\%), while the gap in the training is noticeable already at the initial stages of learning. The Chi-square criterion test showed virtually no differences at the ascertaining stage and significant differences at the control stage of the experiment. The obtained data indicate the effectiveness of the organization of the mathematical training of future managers through the base of the professionally-oriented situational problems on the basis of the research and analysis of the professional activity.

\section{Discussions}

Creative aspects of the task-based education are quite diverse; they penetrate both the creation and solution of the situational problems. The situational problems in a creative way are complex and multifaceted processes of knowledge generation. The creative processes of the situational learning are distinguished from scientific creativity by the fact that knowledge here is not entirely new, although it does not exclude the fact that students may be offered an original solution to the problem.

Creativity consists of a multitude of individual discoveries and insights of future specialists, when the situation analysis is being completed and the ways to solve the situational problem become clear.

\section{Conclusions}

The research states that the efficiency of forming the professional competencies of future specialists may be greatly enhanced if in the learning process the situational problems (task-based method) are used, creating an active, productive, reflective interaction between the subject of the educational process and the educational environment.

At the control stage of the experiment there is a significantly positive dynamics in all the aforementioned criteria. Therefore, the significance of the training activities with the use of the situational problems during the professional training has been revealed.

\section{Acknowledgments}

The authors thank all participants of this study for their kind cooperation. 


\section{References}

Adigamova, E. B. (2014). Learning environments of national research universities. Journal of Basic Research, 5, 378.

Ball, G. A. (1990). The theory of learning tasks: the psychological aspect. Moscow Publisher "Pedagogy", 198.

Bloom, B. S. (1956). Taxonomy of educational objectives: The classification of educational goals: Handbook I, cognitive domain. New York. Longman.

Buharova, G. D. (1996). Theoretical and methodological foundations of learning the challenges of high school students. Author. dis. ... Dr. ped. Science. Ural. state. prof.-ped. Univ. Ekaterinburg, 38.

Dewey J. (1999). Psychology and Pedagogy of thinking (as we think). Moscow Publisher "Pedagogy", 489.

Dewey, J. (2000). Democracy and Education. Moscow Publisher "Psychology Press", 205.

Friedman, L. M. (1977). Logical-psychological analysis of school learning tasks. Moscow Publisher "Pedagogy", 208.

Galperin, P. Y. (1978). Actual problems of psychology. Materials for the course lectures. Moscow Publisher of the Moscow State University, 118.

Kabirov, R. R., \& Sugachkova, E. V. (2005). Assessment of the quality of the environment. A teaching aid. - Ufa Vagant. In the educational-methodical manual provides specific topics of general and specific, proposed forms of organization and methods of laboratory and practical exercises to assess the quality of the environment, 135.

Kalmikova, Z. I. (1981). Productive thinking as a basis for learning. Moscow Publisher "Pedagogy", 200.

Larionov, V. V. (2009). Turing Yu Problem-based learning in a technical college physics. Journal of Higher education in Russia, 6, 152.

Leontiev, A. N. (1983). Selected psychological works: in 2 v. Moscow Publisher "Science", 391.

Lerner, I. J. (1967). Experience of using cognitive tasks in class V. Journal of History teaching in school, 1, 87.

Makhmutov, M. I. (1975). Problem-based learning. Moscow Publisher "Pedagogy", 368.

Matkarimova, D. S. (2012). Technology design case studies in the content of practical training. Journal of Young scientist, 4, 437.

Mukhametzyanova, G. V. (2005). Professional education: Issues of quality and scientific and methodological support. Kazan. Publishing House "Magarif", 320.

Okon, V. (1968). Problem-based learning. lane. with Pol. Publishing House "Education", 208.

Rubinstein, S. L. (1958). On the thinking and ways of its study. Moscow Publishing House of the USSR Academy of Sciences, 230.

Tolsteneva, A. A., (2008). Methodical system of teaching physics university students by taking into account their cognitive styles. PhD Thesis. Nizhny Novgorod, 390.

Vygotsky, L. S. (1996). Educational Psychology. Moscow Publisher "Psychology Press", 544.

Zeer, E. F. (2005). The modernization of vocational education: competence approach. Moscow Publisher MPSI, 216.

Zimnya, I. A. (2006). Competence approach. What is its place in the modern approaches to education? (theoretical and methodological aspect). Journal of Higher education today, 8, 29.

\section{Copyrights}

Copyright for this article is retained by the author(s), with first publication rights granted to the journal.

This is an open-access article distributed under the terms and conditions of the Creative Commons Attribution license (http://creativecommons.org/licenses/by/3.0/). 